\title{
Microclimate buffering of winter temperatures by pine stumps in a temperate forest
}

\author{
Aleksandra Walczyńska ${ }^{1}$ Paweł Kapusta ${ }^{2}$
}

Received: 11 March 2016 / Accepted: 19 May 2016 / Published online: 1 June 2016

(C) The Author(s) 2016. This article is published with open access at Springerlink.com

\begin{abstract}
In the presented study we evaluated the role of wood in buffering its inhabitants against winter temperatures. We followed the microscale temperature patterns inside and outside decaying pine stumps during two winter periods. We analyzed the data by extracting the minimum, maximum and mean temperatures for the episodes of snow, frost or no frost. We compared the temperature variation by applying an absolute values calculation (=modulus) for the subsequent measurements. Finally, we tested the buffering effect of the horizontal depth inside the stumps by comparing the pattern for 5 and $15 \mathrm{~cm}$ depths. The results show that (1) the minimum temperature was significantly higher inside than outside the stumps, while temperature variation tended to be larger outside than inside, (2) the dynamics of temperature varied between weather episodes, i.e. the periods characterized by the presence/absence of snow and of frost, (3) the minimum temperature inside the stumps increased with the horizontal depth, while temperature variation decreased. The results presented are the first truly microclimatic data on wood buffering and they are important for the understanding of the possible effects of climate change on the thermal relationships at the microscale.
\end{abstract}

Keywords Buffering $\cdot$ Decayed wood $\cdot$ Extremes . Microclimate $\cdot$ Modulus $\cdot$ Winter

Aleksandra Walczyńska

aleksandra.walczynska@uj.edu.pl

1 Institute of Environmental Sciences, Jagiellonian University, Gronostajowa 7, 30-387 Kraków, Poland

2 W. Szafer Institute of Botany, Polish Academy of Sciences, Lubicz 46, 31-512 Kraków, Poland

\section{Introduction}

The role of temperature in different aspects of the lives of organisms is a widely discussed issue (Atkinson and Thorndyke 2001; Johnston and Bennett 2008) and becomes even more important in the face of global warming (Helmuth et al. 2005; Dillon et al. 2010; Salinger 2013). Microclimate is an important driver of performance in organisms; recent studies have focused on habitat response to thermal changes at the microscale level (Helmuth 2009; Helmuth and Hofmann 2001; Helmuth et al. 2010; Suggitt et al. 2011; Potter et al. 2013). The microscale environment was found to affect the physiology of mussels in intertidal habitats (Helmuth 1998, 2009), the population dynamics of herbivores in the canopy (Pincebourde et al. 2007; Pincebourde and Woods 2012), and the critical thermal maxima for frog and lizard species in a primary rainforest in the Philippines (Scheffers et al. 2014). Assessing selective pressures in a set of different microhabitats may provide a wider understanding of the general effect of microscale on performance. The present study contributes to this issue by examining the cold buffering effect in decaying wood habitat.

Concerning the possible response to climatic change, the lower end of the thermal continuum is a target for natural selection modulating physiological adaptation to low temperatures, while tolerance to high temperature is more constrained physiologically (Araújo et al. 2013). Since global temperature increase is driven by the rise of daily minimum rather than daily maximum temperatures (Easterling et al. 1997; Vose et al. 2005; Brown et al. 2008), a stronger organismal reaction is expected at minima rather than at maxima of temperature tolerance.

Tree stumps may serve as temporary or permanent habitat for arthropods of different feeding guilds such as woodfeeders, fungivores and predators. At least in the case of 
wood-feeders, this type of habitat is evolutionarily demanding because it requires various mechanisms for dealing with nutritionally poor food (Haack and Slansky 1987). On the other hand, it is remarkably safe; the mortality of wood-feeding larvae is lower than the mortality of larvae from other feeding guilds (Walczynska 2010). Interestingly, the life strategy of a species changes with the horizontal depth of its wood boring niche, likely caused by the heterogeneous environment inside the tree (Walczynska 2012). Although it was shown that wood inhabitants are characterized by a relatively low mortality rate (Haack and Slansky 1987; Walczynska 2010), it is unknown whether this trend is driven by low pathogen and predatory pressure or by high winter survival. Predictions from a theoretical model suggest that cold-induced mortality is one of the key factors driving the population dynamics of the mountain pine beetle Dendroctonus ponderosae (Régnière and Bentz 2007), yet our understanding of the factors shaping the life-history strategies of wood inhabitants is poor. In general, overwintering was advocated as a key component of the biology of organisms inhabiting temperate, polar and alpine regions (Williams et al. 2015).

The role of wood in buffering outside winter temperature has previously been investigated mostly in the context of insect pest species, especially the pine beetle. Therefore, most existing studies examined living pine trees, and temperature data were recorded under the bark of trees. The results are contradictory; some studies showed that the buffering effect of wood can be small $\left(<1{ }^{\circ} \mathrm{C}\right.$ difference for an annual study; Bolstad et al. 1997), or considerable (up to $12{ }^{\circ} \mathrm{C}$ difference for a period of sub-zero temperatures; Beal 1934, after Tran et al. 2007); that it may have a constant effect (Bolstad et al. 1997), or may depend on other environmental factors, as in a two-year study on 60 ash trees by Vermunt et al. (2012). Potter and Andresen (2002) designed a theoretical model of heat flow throughout the tree. However, this model cannot be tested without reliable data on air- and inside-wood temperatures that are generally unavailable. Therefore, more environmental data are needed in this context.

In this study we used dataloggers with two temperature sensors to simultaneously measure the temperature inside and outside partly decayed pine stumps. We monitored temperature changes through two winter seasons. We distinguished 'episodes' within measurement seasons based on the presence/absence of snow and of frost to control for their potentially different effects on wood buffering. For comparison we used different measures of temperature, including extreme and mean values, and a variability measure-a 'temperature modulus' which is a simple statistic based on the absolute differences between consecutive measurements of two thermal datasets. The advantage of this approach is the linearization of the complicated pattern of the rate of temperature change and a straightforward interpretation. Finally, we compared winter temperature patterns at two levels of horizontal depth within the stumps to examine whether wood inhabitants occupying diverse niches (phloem- vs xylem-feeders) may possibly face different selection pressures during winter.

\section{Materials and methods}

\subsection{Study site}

We measured the temperature inside and outside decaying pine stumps, remaining after felling in 2000 , in the 2004/2005 and 2005/2006 winter seasons (different stumps in each season), in the Niepołomice Forest near Krakow, Poland $\left(50^{\circ} 07^{\prime} \mathrm{N}, 20^{\circ} 23^{\prime} \mathrm{E}\right)$. The study site was the same as used previously to investigate the life history strategy of the xylem-feeder Aredolpona rubra (Coleoptera: Cerambycidae; Walczynska 2012), when this area was examined for the presence of larvae and adults (Walczynska 2008, 2010). Moreover, this area was inhabited by other beetle species living in decayed wood e.g., Criocephalus rusticus and Spondylis buprestoides.

\subsection{Study design}

Four stumps (two per winter season), about $60 \mathrm{~cm}$ in diameter and $20 \mathrm{~cm}$ in height, were chosen for the measurements. We recorded the temperature data from 23 November 2004 to 22 February 2005 (for one stump) and to 18 March 2005 (for the other stump), and from 16 December 2005 to 29 April 2006 for the next two stumps. The scheme of the experimental set-up is shown in Fig. 1. We programmed the HOBO H8 dataloggers (Onset, Pocasset, USA) with an accuracy of $\pm 0.7{ }^{\circ} \mathrm{C}$ and a resolution of $0.4{ }^{\circ} \mathrm{C}$ at $21{ }^{\circ} \mathrm{C}$ for hourly measurements. The inside temperature was measured with the external sensors of the dataloggers $(\varnothing 4.7 \mathrm{~mm})$, which were placed inside the stump horizontally in holes $\varnothing 5 \mathrm{~mm}$ in diameter, drilled into the stump to depths of about 5 (in both seasons) and $15 \mathrm{~cm}$ (only in 2005/2006 season) at half of the stump height. The outside temperature was measured with the internal sensors of the dataloggers, which were placed on the soil surface close to the stumps $(c .2 \mathrm{~cm})$. Sensors were delicately covered with the plant litter. Because the sensors were under litter or relatively deep in the stump wood, and the stumps were shaded for most of the time, the effect of solar radiation on the measurements can be neglected. 


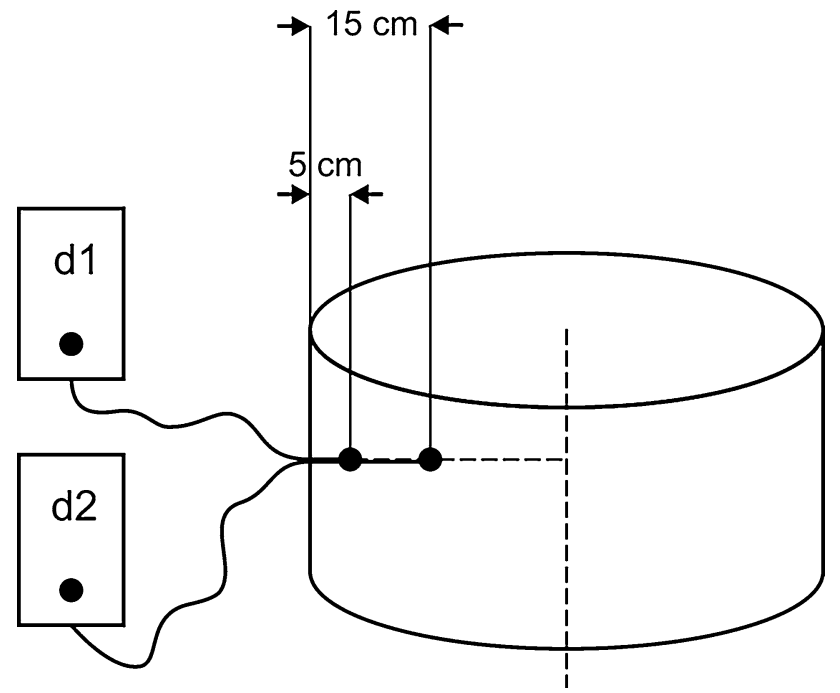

Fig. 1 A diagram representing the experimental setup for the collection of temperature data from stumps. Black dots represent sensors: internal for dataloggers 1 and 2 ( $d 1$ and $d 2$ ), measuring the temperature outside a stump, and external, measuring temperature inside a stump, at two levels of horizontal depth (measurements at $5 \mathrm{~cm}$ were made during both seasons, while measurements at $15 \mathrm{~cm}$ were made in the 2005/2006 season only)

\subsection{Data organization}

We divided the datasets for each winter season into episodes of frost, snow and no frost. Firstly, we categorized days with snow cover as snow episode $(\mathrm{S})$, days without snow cover when the temperature dropped below $0{ }^{\circ} \mathrm{C}$ for $24 \mathrm{~h}$ for at least one sensor as frost episode $(\mathrm{F})$, and the remaining days as no-frost episode (NF). For each day we isolated the minimum and maximum temperatures separately for inside and for outside. For further analysis we calculated the means for the three lowest and three highest daily values, respectively, as $\mathrm{T}_{\min }$ and $\mathrm{T}_{\max }$, and the mean daily values $\left(\mathrm{T}_{\text {mean }}\right)$. Finally, we computed the mean daily absolute values between hourly measurements (daily modulus) according to the formula:

$|T(n)-T(n-1)|=x$,

where $T(n)$ - temperature at time $n ; T(n-1)$-temperature $1 \mathrm{~h}$ before; $x$-a positive (absolute) value of positive or negative difference between two consecutive hourly measurements. The modulus served as a measure of thermal variability because, contrary to statistical variability measures, it has a straightforward biological interpretation.

\subsection{Wood buffering at $5 \mathrm{~cm}$ horizontal depth}

We analysed the variables $\mathrm{T}_{\min }, \mathrm{T}_{\max }, \mathrm{T}_{\text {mean }}$ and modulus for the relationship between inside and outside stumps temperatures in separate analyses. Due to the autocorrelation of all daily measures, the statistical approach was to calculate the means for each episode within each winter season independently; three lowest and three highest values for each episode as $\mathrm{T}_{\min }$ or $\mathrm{T}_{\max }$, respectively, and the means of daily values in the case of $\mathrm{T}_{\text {mean }}$ and modulus. By such an approach in calculating $\mathrm{T}_{\min }$ and $\mathrm{T}_{\max }$, we obtained the seasonal extreme values. We analyzed these data with Repeated Measures ANOVA (SAS, SAS Institute Inc., v.9.4), with the stump as subject, the season as an independent between-subject factor and the episode (three levels) and the location (inside-outside; two levels) as withinsubject factors.

\subsection{Horizontal depth effect}

To estimate the effect of horizontal depth of the stumps (position of a thermocouple) on the buffering of winter temperatures we compared the $\mathrm{T}_{\min }$ and modulus inside the stumps for two horizontal depth levels: 5 and $15 \mathrm{~cm}$. We tested this effect only in one season (2005/2006) and only for days without snow cover (32 consecutive days since 27 March 2006). We inspected the data for time autocorrelation and corrected them (Yule-Walker method, PROC AUTOREG, SAS Institute Inc., v.9.4). We analysed the corrected data using a GLM model with the depth and stumps as fixed factors and the respective values outside the stumps ( $\mathrm{T}_{\min }$ or modulus) as a covariate (Statistica 10, StatSoft).

\subsection{Climatic data}

The following climatic data were additionally used in the analyses: daily snow cover and mean temperature, for the time periods respective to our study, and yearly snow cover and minimum temperature, for the period of 1986-2015. All these data derived from the Łazy Meteorological Station (Institute of Geography and Spatial Management, Jagiellonian University) situated about $14.5 \mathrm{~km}$ south-east of the study site.

\section{Results}

In the 2004/2005 season, the temperature pattern was much more variable (considerable fluctuations) than in the 2005/2006 season (Fig. 2). As the differences might depend on the snow cover, we compared the daily temperature data with the snow cover data. In the 2005/2006 season, thick and long-persisting snow cover dominated the data. A period of higher variability of temperature changes began around the 28th of March, when snow started to melt. The mean and range of temperature values in the $2004 / 2005$ season was $-0.3{ }^{\circ} \mathrm{C}\left(-6.3\right.$ to $\left.6.2{ }^{\circ} \mathrm{C}\right)$, while in 
Fig. 2 The mean daily temperatures inside and outside of pine stumps at $5 \mathrm{~cm}$ depth in the Niepołomice Forest (left $Y$ axis) and daily snow cover from Łazy meteorological station (right Y axis)

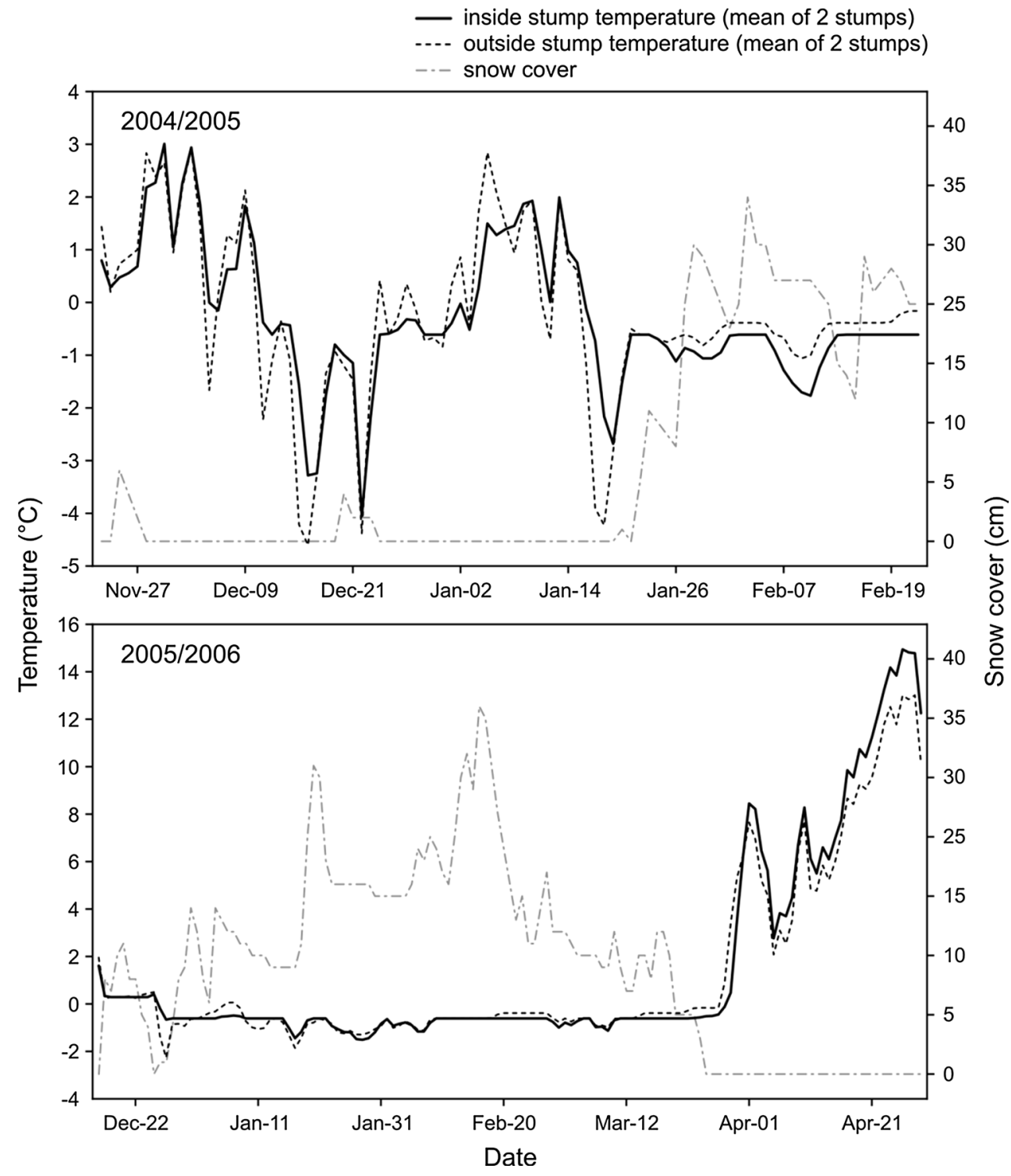

the $2005 / 2006$ season it was $+1.3{ }^{\circ} \mathrm{C}\left(-4.1\right.$ to $\left.24.8{ }^{\circ} \mathrm{C}\right)$. In the 2004/2005 season we distinguished at least 40 (64 for the second stump) days with snow cover, 27 days with frost and 23 days without snow or frost, while in 2005/2006 the respective number of days per episode was 100,3 and 31 . The comparison of daily means for air temperature (climatic data from the meteorological station) and for our "outside temperature" (sensor on the soil, lightly covered with litter), for the respective periods of time, shows that (1) the general pattern of the frequency and direction of temperature changes is very similar in the two datasets in the absence of snow (in the first half of the 2004/2005 season), and (2) the magnitude of these changes is considerably larger for air temperature (Fig. 3). This effect is discussed below.

\subsection{Wood buffering at $5 \mathrm{~cm}$ horizontal depth}

The temperature changes inside the stumps, calculated as absolute values of changes between the hourly measurements, are not only smaller than outside, but also show a more stable and constant pattern ("Appendix"). Because the thermal scale was shifted between winter seasons, the temperature data were standardized prior to the analyses by recalculating to the units of standard deviation, for each season independently. The results of the Repeated Measures ANOVA (Table 1) show a consistent and considerable effect of episode factor and its interaction with the season. The temperature inside and outside the stumps differed statistically in the case of $\mathrm{T}_{\min }$. Minimum temperature was lower outside the stumps and this pattern changed with 
Fig. 3 The comparison of daily means for air temperature (meteo data) and for outside stump microclimatic data (our data, mean of two stumps) during the period of temperature measurements

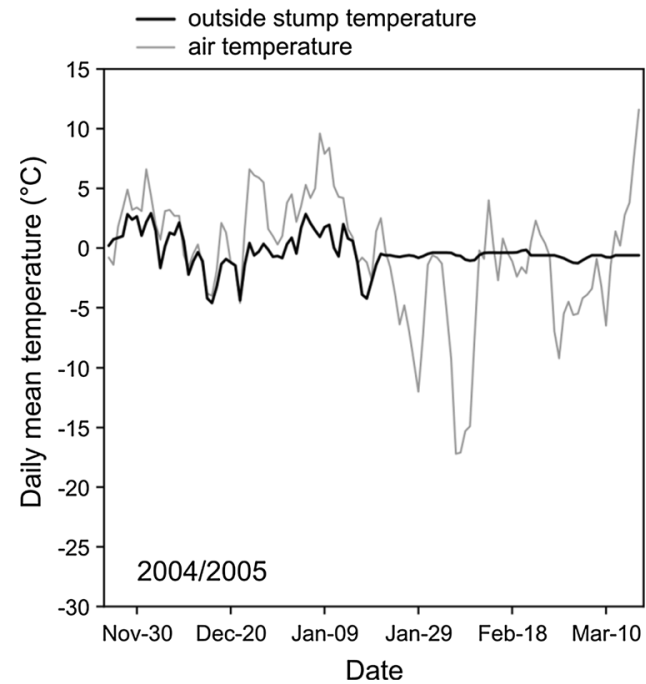

Table 1 Effects of the season (2004/2005 vs 2005/2006), the episode (snow vs frost vs no frost), the location (inside vs outside a stump) and interactions of these factors on the minimum, maximum and mean temperature as well as the thermal variability (modulus) as revealed by the Repeated Measures ANOVA

\begin{tabular}{lrrrr}
\hline Factor & \multicolumn{1}{c}{$\mathrm{T}_{\min }$} & \multicolumn{1}{l}{$\mathrm{T}_{\max }$} & \multicolumn{1}{l}{$\mathrm{T}_{\text {mean }}$} & Modulus \\
\hline Season & $\mathbf{0 . 0 0 1 3}$ & 0.1308 & 0.1252 & 0.0814 \\
Episode & $<\mathbf{0 . 0 0 0 1}$ & $<\mathbf{0 . 0 0 0 1}$ & $<\mathbf{0 . 0 0 0 1}$ & $\mathbf{0 . 0 0 0 2}$ \\
Episode $\times$ season & $<\mathbf{0 . 0 0 0 1}$ & $\mathbf{0 . 0 0 0 4}$ & $\mathbf{0 . 0 2 4 4}$ & $\mathbf{0 . 0 0 1 1}$ \\
Location & $\mathbf{0 . 0 0 9 6}$ & 0.2132 & 0.7232 & 0.0971 \\
Location $\times$ season & 0.0592 & 0.5773 & $\mathbf{0 . 0 1 3 9}$ & 0.7879 \\
Episode $\times$ location & $\mathbf{0 . 0 0 9 7}$ & 0.3380 & $\mathbf{0 . 0 1 3 3}$ & 0.1964 \\
Episode $\times$ location $\times$ season & $\mathbf{0 . 0 1 1 4}$ & 0.6375 & $\mathbf{0 . 0 1 6 7}$ & 0.6467 \\
\hline
\end{tabular}

Bold values represent $p<0.05$

episode and season (Table 1, Fig. 4; exact temperature values are given above). A tendency $(p<0.1)$ towards differences in location was also observed in modulus, which was generally higher outside, but was most probably masked by the considerable between-stump variation in temperature changes outside of the stumps (Fig. 4). Neither $\mathrm{T}_{\max }$ nor $\mathrm{T}_{\text {mean }}$ differed in temperature regarding datalogger location (Table 1). However, in the case of $\mathrm{T}_{\text {mean }}$, location significantly interacted with season, episode, as well as with both (Table 1; Fig. 4). Overall, the pattern found was driven by differences among seasons, especially by the very short (3 day) frost episode in the 2005/2006 winter.

\subsection{Horizontal depth effect}

The horizontal depth of the internal measurements, analysed for the period without snow cover, with the lowest temperature recorded equal to $-0.61{ }^{\circ} \mathrm{C}$, affected both the minimum temperature and the temperature variation. In the former case, the internal temperature was affected by depth $(p=0.018)$, with the external minimum temperature as a covariate $(p<0.001)$. Overall, the minimum temperature inside the stumps measured at a horizontal depth of $15 \mathrm{~cm}$ and adjusted for the outside temperature was $4.6^{\circ} \mathrm{C}$ and was significantly higher than at $5 \mathrm{~cm}$ depth (adjusted, $3.2{ }^{\circ} \mathrm{C}$ ). The temperature variation (modulus) inside the stumps was affected by depth $(p<0.001)$, stumps $(p=0.001)$ with the external variation as a covariate $(p<0.001)$. Temperature changes inside the stumps were significantly higher at $5 \mathrm{~cm}$ horizontal depth (adjusted for outside conditions, 8.2) compared to $15 \mathrm{~cm}$ (adjusted, 7.1).

\section{Discussion}

The results of the temperature measurements inside and outside (in shallow litter) decaying pine stumps in Niepołomice Forest (Poland) during two winter seasons show that (1) a buffering effect in winter operated against minimum values (Table 1; Fig. 4), and (2) that the horizontal depth inside the stumps analysed for the period without snow cover affected both the minimum temperature and variation in temperature. Overall, the minimum outside temperature in shallow litter was about $1{ }^{\circ} \mathrm{C}$ lower than inside the stumps at $5 \mathrm{~cm}$ horizontal depth. Additionally, we observed a tendency for higher thermal variability (about 1.7 times overall) outside versus inside the stumps. The maximum temperature was not significantly different with respect to sensor location. However, it tended to be consistently higher outside (Fig. 4). This slight difference was most probably not statistically detected because of the small sample size. The complicated temperature dynamics are best illustrated in the case of $\mathrm{T}_{\text {mean }}$, which, though not different (as it was standardized) among seasons or sensor locations, significantly 
Fig. 4 Means and $0.95 \mathrm{CI}$ of four different temperature parameters calculated for $2004 / 2005$ and 2005/2006 seasons, inside (black) and outside (grey) sensor locations, and the three weather episodes ( $S$ snow, $F$ frost, $N F$ no frost). The $p$ values refer to the third level interaction of the repeated measures ANOVA (cf. Table 1)
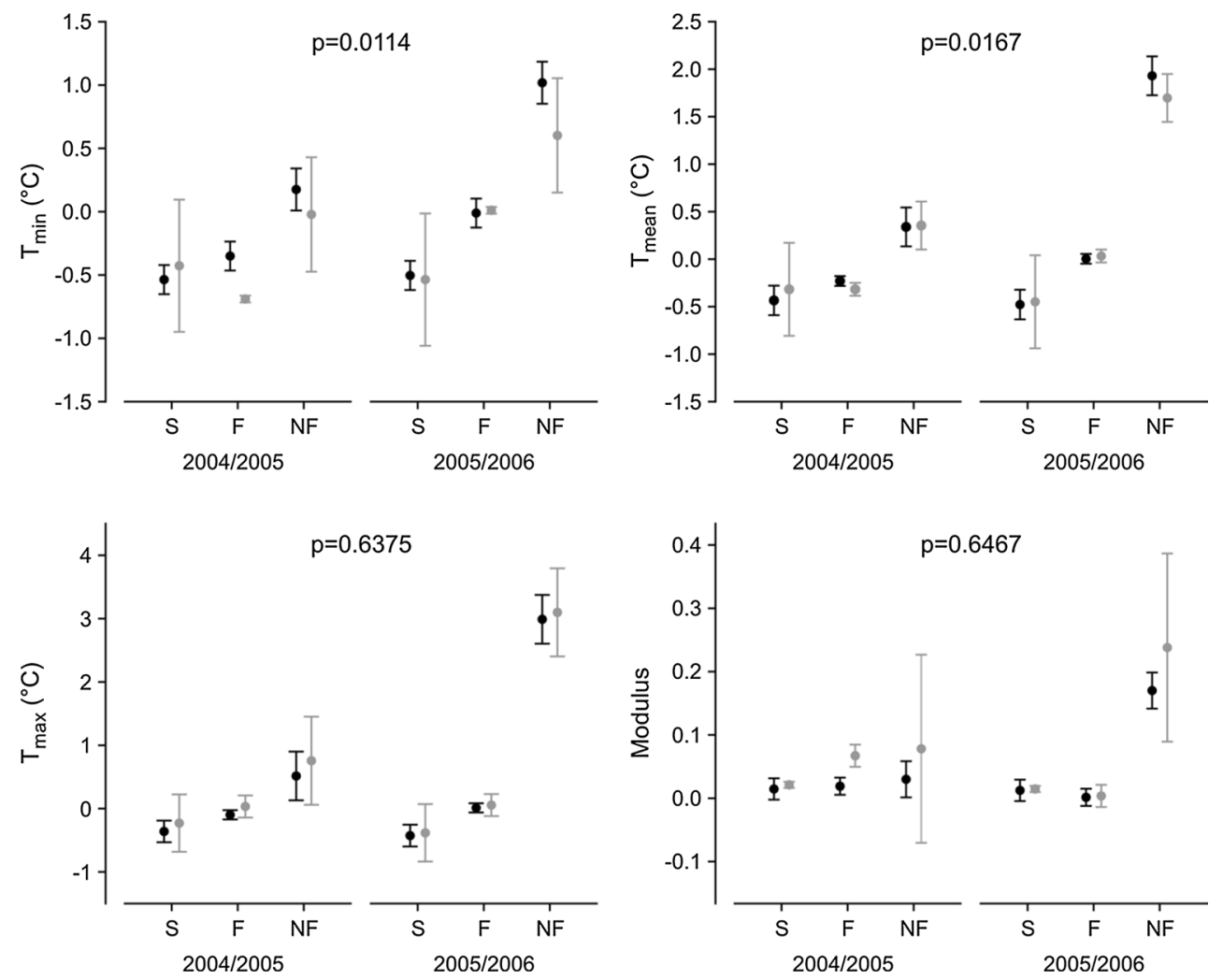
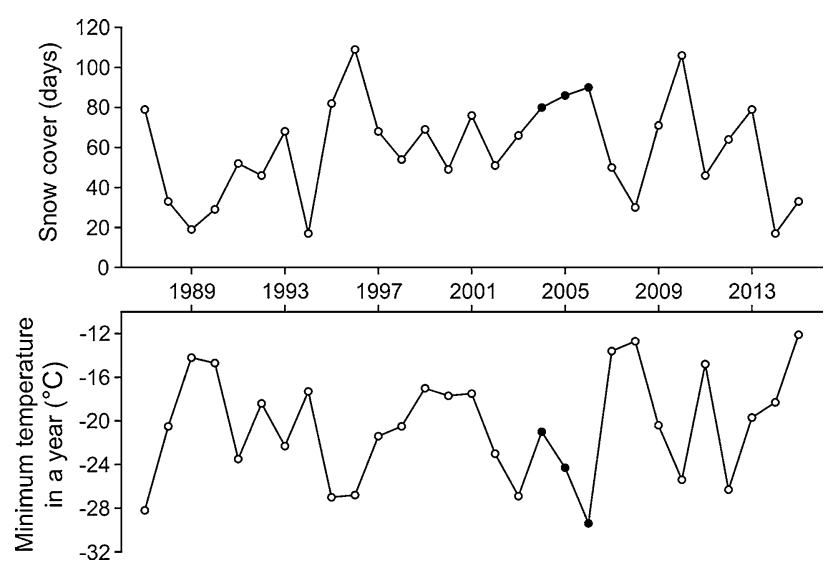

Fig. 5 The number of days with snow cover within a year (upper panel) and the minimum air temperature within a year (lower panel) for the 30-year period. Data from the Łazy meteorological station. Black dots correspond to the measurement seasons in this study (note that the values presented refer to "years", not to "winters")

interacted with episodes and their interactions with other factors (Table 1; Fig. 4). The representative value of our measurements period within the space of 30 years is shown in Fig. 5. According to this illustration, the winters in our study were relatively cold and relatively snowy.

Mainly minimum and maximum temperatures were analysed in similar studies. While the results on the buffering effect of wood against minimum winter temperatures are unequivocal (Bolstad et al. 1997; Tran et al. 2007; Vermunt et al. 2012), maximum temperature values were found to be higher inside (Bolstad et al. 1997; Vermunt et al. 2012), or higher outside the trees (Tran et al. 2007). Apart from examining the extreme and mean values, we also took into account the general thermal variability pattern inside and outside stumps. This important issue has not been examined before, although some theoretical models of insect overwintering strategies showed that including the daily thermal variability statistically improved the model fit (Régnière and Bentz 2007).

The main difference between our approach and previous investigations is that the air temperature in the latter was measured in weather stations close to the study areas. In consequence, comparisons between inside-tree and air temperature might have been inaccurate because of temporal and spatial measurement distance and possibly because of the different resolutions of the devices used. The magnitude of difference in comparing inside-outside data between a microscale and a larger spatial scale is best illustrated in Fig. 3, showing air temperature data derived from the nearest meteorological station contrasted with our outside-stump temperature data. This comparison validates (1) the reliability of our "outside" measurements, because the general pattern of the frequency and direction of temperature variation is very similar for the two datasets in the absence of snow (compare with Fig. 2), (2) the importance of taking the snow cover into account, and (3) the truly microclimatic meaning of our results. The difference in 
the magnitude of changes between air and outside stumps temperature may be caused by the contact of our external sensor with the ground or with litter cover, but most probably it is the effect of the buffering by the forest itself. This result strongly supports the recommendation that a reliable study on the buffering effect in a given habitat demands a microscale. This is important if an attempt is made to link temperature changes in time with possible effects on organism growth or survival; in the case of our study, the difference in temperature between air and the wood microsite combines the effects of forest, snow, frost and niche occupied within wood. It is also worth mentioning that wind appeared to be the main factor affecting soil temperature pattern in a study by Ashcroft et al. (2009).

The results of our study, attempting a comprehensive assessment of winter temperature dynamics inside decaying stumps, have important consequences for the overwintering strategies of wood inhabitants. The division into winter episodes supports the already well-known dominating effect of snow (Sinclair 2001; Bale and Hayward 2010). This effect may be critical for woodfeeders exploiting the tree at different heights, such as Marmara sp. species (Lepidoptera: Gracillariidae) or three bark beetles (Coleoptera: Curculionidae): Dendroctonus valens, Ips pini and Pityogenes hopkinsi (Price 1984). Distinctive cold-hardening strategies may be expected in such cases. The interacting effect of temperature and snow in determination of microclimatic conditions and, further, of overwintering strategies of organisms was recently discussed by Williams et al. (2015). Moreover, we show the importance of the no-frost episode, which may interrupt frost and snow episodes. Such interruptions occurred in the 2004/2005 season in our study, and their existence may be an indication of climate warming (e.g. Sinclair 2001). The difference between inside and outside temperatures, for all the variables tested, was the most distinct in this type of episode (Fig. 4). Warm periods during winter may substantially affect the survival of overwintering organisms. A freeze-tolerant organism would be exposed to more freeze-thaw cycles, increasing mortality (Sinclair 2001; Bale and Hayward 2010). On the other hand, a chill-sensitive organism not acclimated to low temperatures, such as an invasive species, would endure cold injury and survive better (Nedvĕd et al. 1998). Considering the buffering effect of decayed wood against minimum temperature and possibly against temperature variation, which we report in this study, we conclude that in the face of climate warming the inside-stump community will be less affected (or at a slower rate) by the negative consequences for native species and by invasions of chill-sensitive foreign species, than the shallow litter community.

In previous studies, the buffering effect of wood was estimated under the bark. Here, we present for the first time a comparison of the temperature inside wood measured at two levels of horizontal depth. The results show that in the absence of snow, deeper parts of the stumps are better protected against both minimum temperature and thermal variability. This conclusion has important consequences for organisms occupying different inside-wood niches; diverse overwintering strategies might be expected in such cases.

Sinclair et al. (2003) specified the aspects of the winter environment that affect winter survival. These include extreme temperatures, the rates at which they are approached, and the fluctuation patterns. According to our results, at least the first factor, and possibly the last, are buffered inside decaying wood in comparison to the surrounding shallow litter. This might have consequences for the entire inside-wood community because this type of environment prevents the migration of its inhabitants, especially among strict wood-feeders. The adjustment to external temperatures by behaviour (migration) may be facilitated in shallow litter. For example, beetle species may show different abilities to vertical migration to deeper soil in response to external temperature (Hoshikawa et al. 1988).

Finally, our results contribute to the issue of climate refugia, created by the heterogeneity of temperature pattern at the landscape scale (Ashcroft et al. 2009). Decaying stumps with their relatively mild and stable conditions may act as archipelagos on the cold forest ocean for organisms not obligatory related to wood such as spiders, predaceous beetles, millipedes etc. Incidentally, this constitutes another argument in favour of saving wooden debris in forests of economic importance.

In summary, arthropods overwintering inside tree stumps are well-protected against minimum winter temperatures and possibly against high temperature variability. The horizontal depth in stumps affects the general pattern; deeper parts of the stumps are better protected against lowest temperatures and against temperature variability compared to shallower parts of the stumps. This suggests that phloem- and xylem-feeders face different temperature regimes during winter, at least during snow-free intervals. Finally, the periods with and without frost or snow have different temperature dynamics, and this issue opens a new line of inquiry for testing overwintering strategies.

Acknowledgments We thank January Weiner for suggesting the topic of this study, Łukasz Sobczyk for assistance in the field, Szymon Drobniak and Paweł Koteja for their advice on statistical analysis, Krzysztof Argasiński for his idea to analyse the absolute value of temperature changes and two anonymous reviewers for valuable comments on previous version of the text. Radek Brzezowski and Maciej Pabijan edited the text. The climatic data were kindly provided by Mariusz Klimek from the Łazy Field Research Station of the Institute of Geography and Spatial Management, Jagiellonian University. The work was supported by the Polish Ministry of Science and Higher Education (2 P04C 08328) and by Jagiellonian University (DS/WBiNoZ/INoS 757/13).

Open Access This article is distributed under the terms of the Creative Commons Attribution 4.0 International License (http://creativecommons.org/licenses/by/4.0/), which permits unrestricted use, distribution, and reproduction in any medium, provided you give appropriate credit to the original author(s) and the source, provide a link to the Creative Commons license, and indicate if changes were made. 


\section{Appendix}

See Fig. 6.
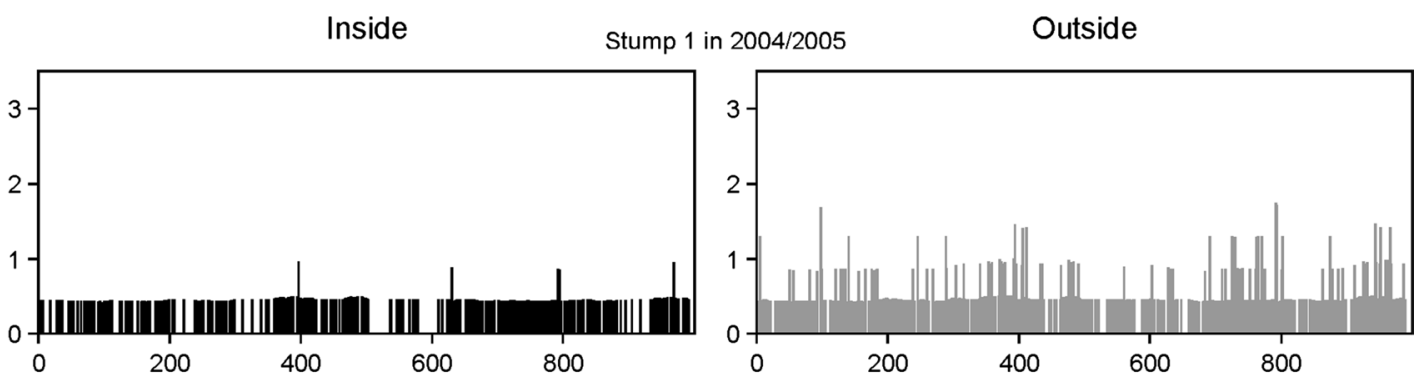

Stump 2 in 2004/2005
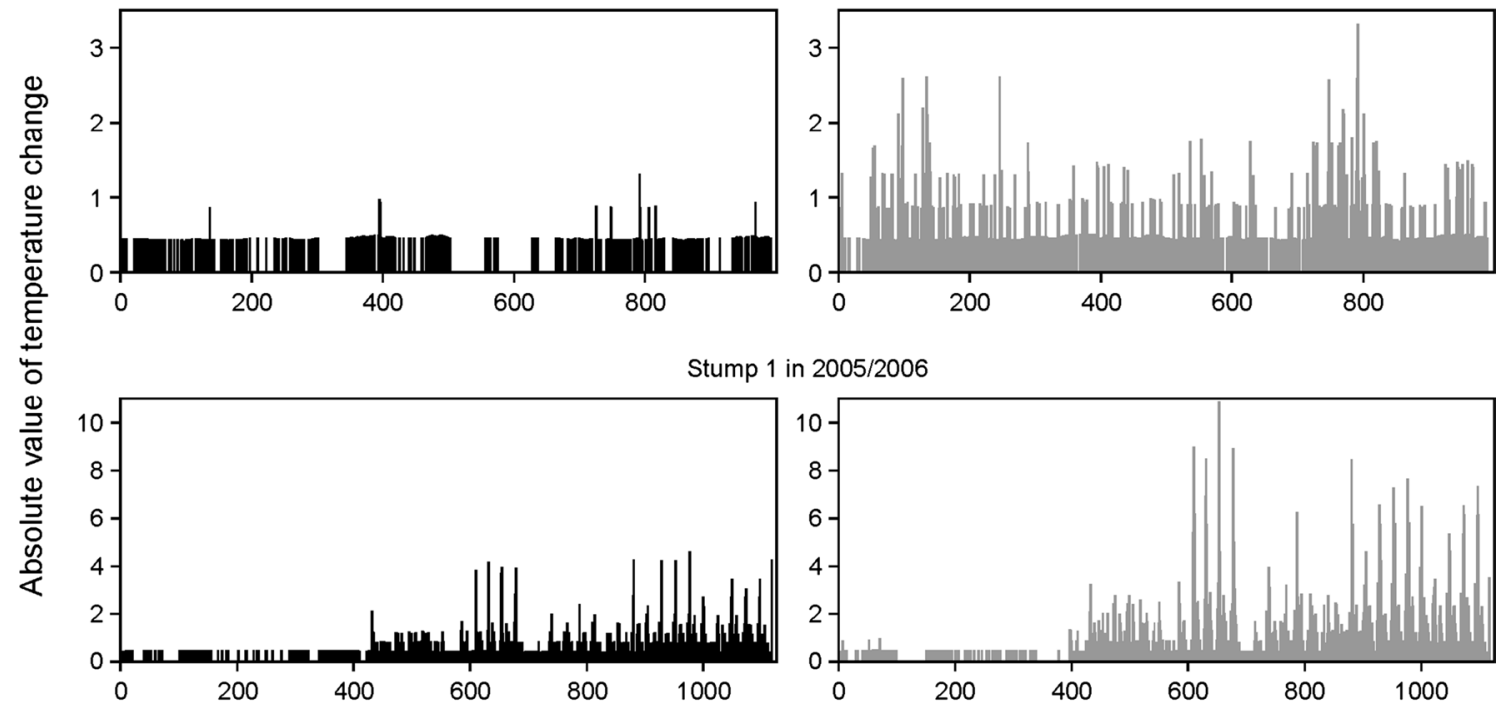

Stump 2 in 2005/2006
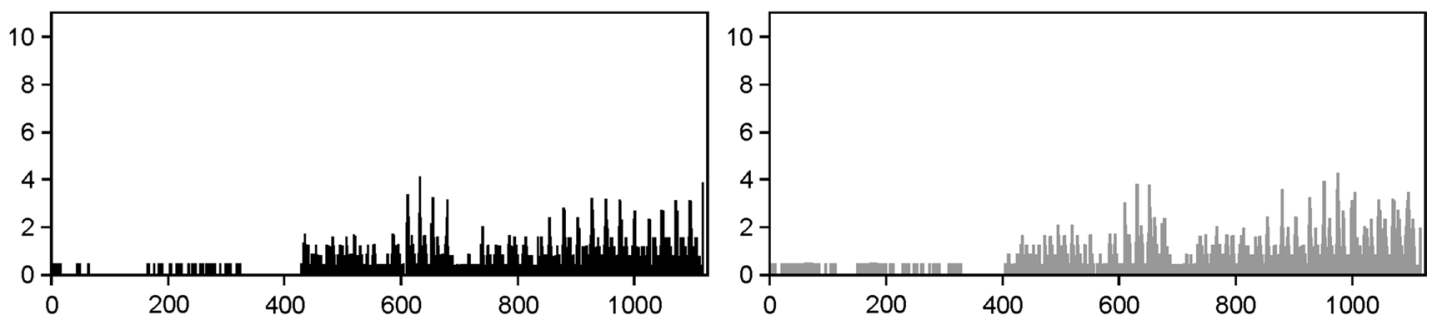

Unit of time

Fig. 6 The absolute values of the differences between the successive temperature values for inside at $5 \mathrm{~cm}$ depth (left column) and outside (right column) the pine stumps. For the sake of clarity of the figures,

\section{References}

Araújo MB, Ferri-Yáñez F, Bozinovic F, Marquet PA, Valladares

F, Chown SL (2013) Heat freezes niche evolution. Ecol Lett 16:1206-1219. doi:10.1111/ele.12155 data where the temperature change was 0 for all four datasets within a season were omitted

Ashcroft MB, Chisholm LA, French KO (2009) Climate change at the landscape scale: predicting fine-grained spatial heterogeneity in warming and potential refugia for vegetation. Glob Change Biol 15:656-667. doi:10.1111/j.1365-2486.2008.01762.x

Atkinson D, Thorndyke M (2001) Environment and animal development. BIOS Scientific Publishers, Oxford 
Bale JS, Hayward SAL (2010) Insect overwintering in a changing climate. J Exp Biol 213:980-994. doi:10.1242/jeb.037911

Beal JA (1934) Relation of air and bark temperatures of infested ponderosa pines during subzero weather. J Econ Entomol 27:1132-1139

Bolstad PV, Bentz BJ, Logan JA (1997) Modelling micro-habitat temperature for Dendroctonus ponderosae (Coleoptera: Scolytidae). Ecol Model 94:287-297. doi:10.1016/S0304-3800(96)00021-X

Brown SJ, Caesar J, Ferro CAT (2008) Global changes in extreme daily temperature since 1950. J Geophys Res 113:D05115. doi: 10.1029/2006JD008091

Dillon ME, Wang G, Huey RB (2010) Global metabolic impact of recent climate warming. Nature 467:704-707. doi:10.1038/ nature09407

Easterling DR, Horton B, Jones PD, Peterson TC, Karl TR, Parker DE, Salinger MJ, Razuvayev V, Plummer N, Jamason P, Folland CK (1997) Maximum and minimum temperature trends for the globe. Science 277:364-367. doi:10.1126/science.277.5324.364

Haack RA, Slansky F Jr (1987) Nutritional ecology of wood-feeding Coleoptera, Lepidoptera and Hymenoptera. In: Slansky F Jr, Rodriguez JG (eds) Nutritional ecology of insects, mites, spiders and related invertebrates. Wiley Sons, London, pp 449-486

Helmuth B (1998) Intertidal mussel microclimates: predicting the body temperature of a sessile invertebrate. Ecol Monogr 68:51-74

Helmuth B (2009) From cells to coastlines: how we use physiology to forecast the impacts of climate change? J Exp Biol 212:753-760. doi: $10.1242 /$ jeb.023861

Helmuth B, Hofmann GE (2001) Microhabitats. Thermal heterogeneity, and patterns of physiological stress in the rocky intertidal zone. Biol Bull 201:374-384

Helmuth B, Kingsolver JG, Carrington E (2005) Biophysics, physiological ecology, and climate change: does mechanism matter? Annu Rev Physiol 67:177-201. doi:10.1146/annurev. physiol.67.040403.105027

Helmuth B, Broitman BR, Yamane L, Gilman SE, Mach K, Mislan KAS, Denny MW (2010) Organismal climatology: analyzing environmental variability at scales relevant to physiological stress. J Exp Biol 213:995-1003. doi:10.1242/jeb.038463

Hoshikawa K, Tsutsui H, Honma K, Sakagami SF (1988) Cold resistance in four species of beetles overwintering in the soil, with notes on the overwintering strategies of some soil insects. Appl Entomol Zool 23:273-281. doi:10.1303/aez.23.273

Johnston IA, Bennett AF (2008) Animals and temperature. Phenotypic and evolutionary adaptation. Cambridge University Press, Cambridge

Nedvĕd O, Lavy D, Verhoef HA (1998) Modelling the time-temperature relationship in cold injury and effect of high-temperature interruptions on survival in a chill-sensitive collembolan. Funct Ecol 12:816-824. doi:10.1046/j.1365-2435.1998.00250.x

Pincebourde S, Woods HA (2012) Climate uncertainty on leaf surfaces: the biophysics of leaf microclimates and their consequences for leaf-dwelling organisms. Funct Ecol 26:844-853. doi:10.1111/j.1365-2435.2012.02013.x
Pincebourde S, Sinoquet H, Combes D, Casas J (2007) Regional climate modulates the canopy mosaic of favourable and risky microclimates for insects. J Anim Ecol 76:424-438. doi:10.1111/j.1365-2656.2007.01231.x

Potter KA, Andresen JA (2002) A finite-difference model of temperatures and heat flow within a tree stem. Can J For Res 32:548555. doi:10.1139/x01-226

Potter KA, Woods HA, Pincebourde S (2013) Microclimatic challenges in global change biology. Glob Change Biol 19:29322939. doi: $10.1111 / \mathrm{gcb} .12257$

Price PW (1984) Insect ecology, 2nd edn. Wiley, London

Régnière J, Bentz B (2007) Modeling cold tolerance in the mountain pine beetle, Dendroctonus ponderosae. J Insect Physiol 53:559_ 572. doi:10.1016/j.jinsphys.2007.02.007

Salinger J (2013) Living in a warmer world. How a changing climate will affect our lives. CSIRO Publishing, Collingwood

Scheffers BR, Edwards DP, Diesmos A, Williams SE, Evans TA (2014) Microhabitats reduce animal's exposure to climate extremes. Glob Change Biol 20:495-503. doi:10.1111/ gcb. 12439

Sinclair BJ (2001) Field ecology of freeze-tolerance: interannual variation in cooling rates, freeze-thaw and thermal stress in the microhabitat of the alpine cockroach Celatoblatta quinquemaculata. Oikos 93:286-293. doi:10.1034/j.1600-0706.2001.930211.x

Sinclair BJ, Vernon P, Klok CJ, Chown SL (2003) Insects at low temperatures: an ecological perspective. Trends Ecol Evol 18:257262. doi:10.1016/S0169-5347(03)00014-4

Suggitt AJ, Gillingham PK, Hill JK, Huntley B, Kunin WE, Roy DB, Thomas CD (2011) Habitat microclimates drive finescale variation in extreme temperatures. Oikos 120:1-8. doi:10.1111/j.1600-0706.2010.18270.x

Tran JK, Ylioja T, Billings RF, Régnière J, Ayres M (2007) Impact of minimum winter temperatures on the population dynamics of Dendroctonus frontalis. Ecol Appl 17:882-899

Vermunt B, Cuddington K, Sobek-Swant S, Crosthwaite JC, Lyons DB, Sinclair BJ (2012) Temperatures experienced by woodboring beetles in the under-bark microclimate. For Ecol Manag 269:149-157. doi:10.1016/j.foreco.2011.12.019

Vose RS, Easterling DR, Gleason B (2005) Maximum and minimum temperature trends for the globe: an update through 2004. Geophys Res Lett 32:L23822. doi:10.1029/2005GL024379

Walczynska A (2008) Female reproductive strategy in the longhorned beetle Corymbia rubra (Coleoptera, Cerambycidae). Norw J Entomol 55:25-30

Walczynska A (2010) Is wood safe for its inhabitants? Bull Entomol Res 100:461-465. doi:10.1017/S0007485309990514

Walczynska A (2012) How does a xylem feeder maximize its fitness? Bull Entomol Res 102:644-650. doi:10.1017/S0007485312000296

Williams CM, Henry HAL, Sinclair BJ (2015) Cold truths: how winter drives responses of terrestrial organisms to climate change. Biol Rev 90:214-235. doi:10.1111/brv.12105 